\title{
The Asian tiger hunts in Maputo city-the first confirmed report of Aedes (Stegomyia) albopictus (Skuse, 1895) in Mozambique
}

\author{
Ayubo Kampango* and Ana Paula Abílio
}

\begin{abstract}
Background: Increasing evidence suggests that dengue fever is endemic in Mozambique. Larvae of both the Afrotropical vector Aedes aegypti and its subspecies, Ae. aegypti formosus, have been reported from three provinces in Mozambique, two of which recently experienced dengue outbreaks. Despite reports of the invasive Oriental vector Ae. albopictus on the islands in the Mozambique Channel and nearby Indian Ocean, the species has not yet been reported in Mozambique.

Findings: Four host-seeking female mosquitoes, collected biting the authors in an urban neighbourhood of Maputo City in the late afternoon of 6 December, 2015, are herein morphologically confirmed as Ae. albopictus.

Conclusion: This is the first report confirming the occurrence in Mozambique of Ae. albopictus, an invasive species and an important vector of human arboviruses. In view of its potential role as a vector of dengue, Chikungunya and Zika viruses, studies are urgently needed to assess the geographical expansion and relative abundance of these important vectors to better understand the potential transmission impact of arboviruses that are efficiently transmitted and globally spread by these vectors.
\end{abstract}

Keywords: Aedes albopictus, New record, Dengue, Chikungunya, Maputo City, Mozambique

\section{Background}

Mozambique reported its first dengue (DEN) fever epidemics in 1984 and 1985 [1]. These were attributed to dengue virus serotype 3 (DENv-3), and evidenced the first DENv-3 transmission to man [1]. Following these outbreaks, the disease remained somewhat dormant until the first trimesters of 2014 and 2015, when two further dengue outbreaks occurred [2]. Recent detection of chikungunya virus $(\mathrm{CHIKv})$ in acute febrile patients [3] strongly suggests that both DENv and CHIKv strains may be cocirculating in some northern and southern regions of the country, particularly in Pemba, and the capital city of Maputo [3].

The transmission of DEN and CHIK in Africa is attributed to the presence of the highly effective Afrotropical vector Aedes (Stegomyia) aegypti (Linnaeus, 1762) [4-6], which is abundant in urban and peri-urban areas

\footnotetext{
* Correspondence: akampango@gmail.com

Laboratório de Entomologia, Instituto Nacional de Saúde (INS), Av. Eduardo Mondlane / Allende, no 1008, C.P. 246, Maputo, Mozambique
}

throughout the tropics and subtropics [7, 8]. Aedes aegypti was first documented in Mozambique in 1960 [9] and since then, larvae of both Ae. aegypti and its subspecies Ae. (Stg.) aegypti formosus (Walker, 1848) have been reported from Maputo, Nampula and Cabo Delgado provinces [10]. The forest form Ae. aegypti formosus utilises tree holes and other natural larval sites and is considered predominantly zoophilic, whereas Ae. aegypti is highly adapted to man, breeding in small natural and artificial water collections in urban / semi-urban regions where it is highly anthropophilic $[4,11,12]$. The relative roles of these subspecies and other local potential vector taxa in dengue outbreaks in Mozambique are yet to be fully elucidated.

It is well documented that the leading Oriental arbovirus vector Ae. (Stg.) albopictus (Skuse, 1895), native to SE Asia and islands of the western Pacific and Indian Ocean [13, 14], is successfully invading tropical and temperate regions worldwide. Facilitated by its egg desiccation tolerance and bionomic plasticity [15], the species has successfully been introduced and become established globally by means of goods transportation, particularly through international 


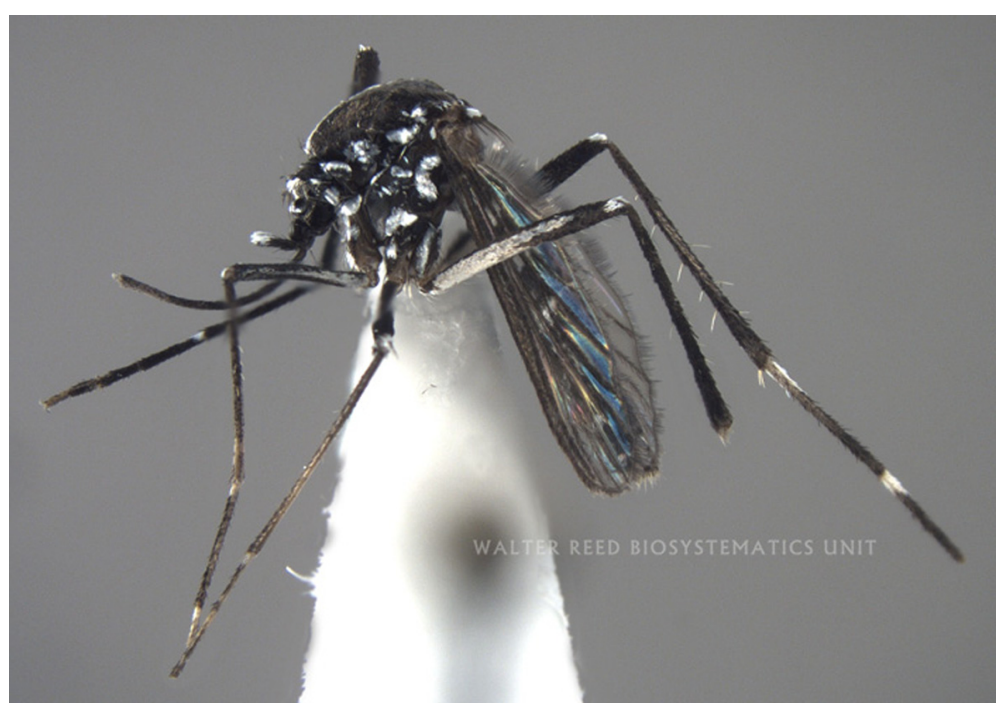

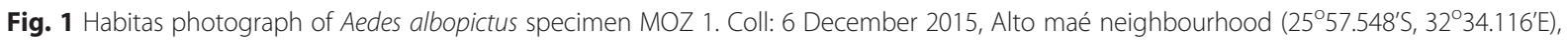
Mozambique. Ayubo Kampango \& Ana Paula Abílio, 14:00-16:00. Photograph by J. Stoffer (WRBU)

trade of used tires [16, 17] and flowers [18]. These introductions are of particular concern as Ae. albopictus is an efficient vector of at least 26 viruses affecting man, including dengue, chikungunya, zika, yellow fever and Japanese encephalitis $[19,20]$, as well as some medically important filarial parasites, e.g. Dirofilaria immitis [21]. Nationwide arbosurveillance activities carried out between 1957 and 1959 did not detect the presence of Ae. albopictus in Mozambique [9]. However, the species has been found and incriminated as DEN and CHIK vectors on islands in the Mozambique Channel and nearby Indian Ocean [22, 23], and a recent modelling study indicated Mozambique as highly suitable for the establishment of Ae. albopictus populations [8].

\section{Findings}

On the afternoon of December 6, 2015, the authors were gathered outdoors with three friends for a social gathering on the patio of an inhabited house in the densely inhabited Alto maé neighbourhood $\left(25^{\circ} 57.548^{\prime} \mathrm{S}, 32^{\circ} 34.116^{\prime} \mathrm{E}\right)$ of Maputo, the capital city of Mozambique. Noting the unusually aggressive mosquitoes attacking their forearms and ankles, the authors collected the host-seeking females using hand-held aspirators. Four females collected between 14:00 and 16:00 were later tentatively identified as the exotic species, Ae. albopictus. Given this preliminary finding, further resting collections were undertaken in tyres and a discarded laundry tank around the property from 14:00 and 16:00 for the two following days (December 7 and 8, 2015), in an attempt to collect more specimens. Outdoor resting collections yielded an additional 21 samples, all later

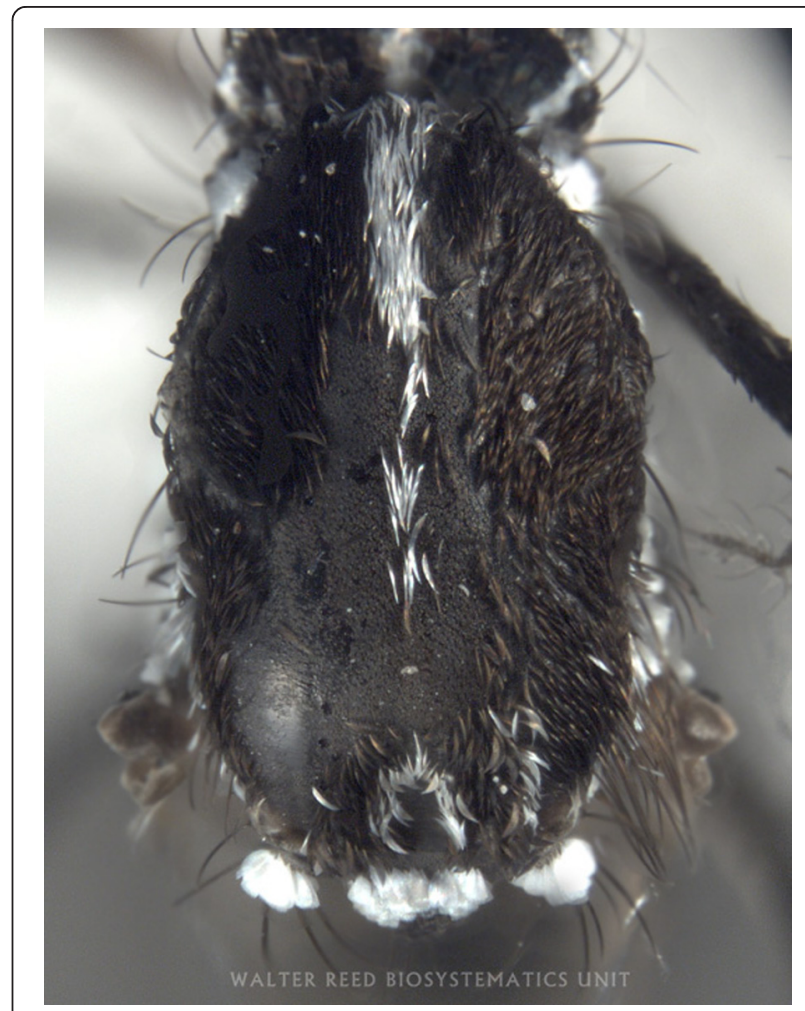

Fig. 2 Dorsal view of thorax of Aedes albopictus specimen MOZ 1. Coll: 6 December 2015, Alto maé neighbourhood (25⒌57.54'S, $\left.32^{\circ} 34.116^{\prime} \mathrm{E}\right)$, Mozambique. Ayubo Kampango \& Ana Paula Abílio, 14:00-16:00. Photograph by J. Stoffer (WRBU) 


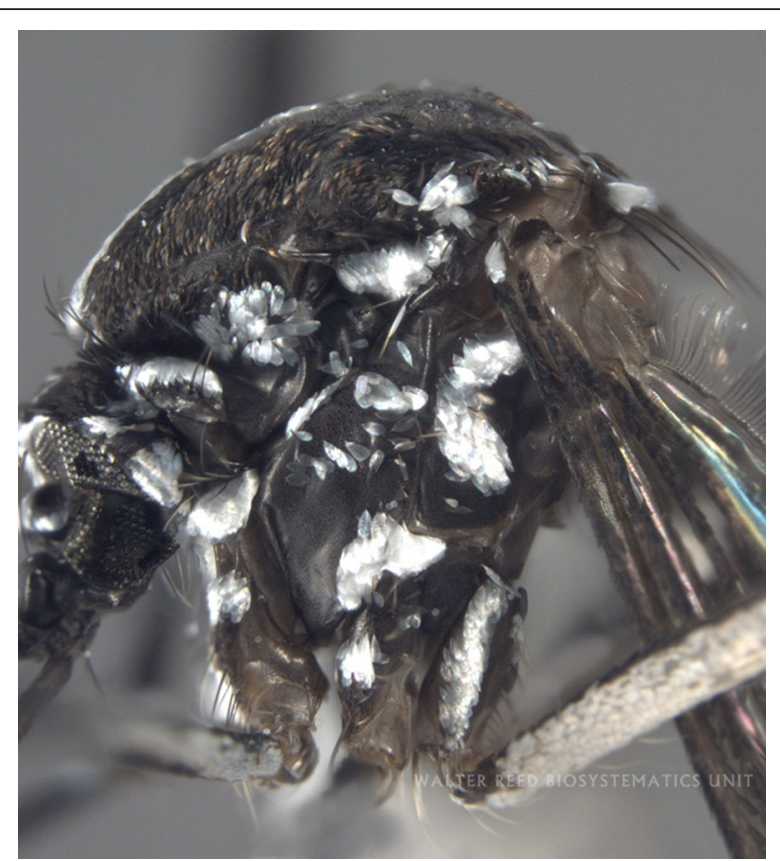

Fig. 3 Lateral view of thorax of Aedes albopictus specimen MOZ 1. Coll: 6 December 2015, Alto maé neighbourhood (25⒌57.54'S, $32^{\circ} 34.116^{\prime}$ E), Mozambique. Ayubo Kampango \& Ana Paula Abílio, 14:00-16:00. Photograph by J. Stoffer (WRBU)

identified as Culex (Culex) quinquefasciatus Say 1823; no larval sites were detected in the surrounding gardens.

Suspected Ae. albopictus samples $(n=4)$ were taken to the Laboratory of Entomology, National Institute of Health (INS) in Maputo City for independent morphological identification by both authors using available taxonomic keys [11, 24, 25]. Specimens 1 (good specimen; see Fig. $1 \mathrm{a}-\mathrm{c}$ ) and 3 were later sent to Dr Yiau-Min Huang (Walter Reed Biosystematics Unit, Maryland, USA) who verified the identifications, thus confirming the presence of Ae. albopictus in Mozambique for the first time. Voucher specimens of the four Ae. albopictus collected in this study are deposited in the insect repository of National Institute of Health (INS) in Maputo City, Mozambique. Specimens 1 and 3 are card-point mounted on insect pins, whereas specimens $2 \& 4$ are stored in individual Eppendorf ${ }^{\circ}$ tubes. A full habitas photograph (Fig. 1) as well as dorsal (Fig. 2) and lateral views (Fig. 3) of the voucher specimen MOZ 1 are shown; equivalent photographs for voucher specimen MOZ 3 (not shown) are held by the authors.

Although some characters were rubbed in some specimens, the samples consistently exhibited the following unique morphological characters of Ae. albopictus as described by Huang [11, 24, 25] and listed (with permission) for clarity below: “...Head: Palpus approximately 0.2 length of proboscis, with white scales on apical half (Fig. 1).
Thorax: Scutum with a prominent median stripe which narrows slightly posteriorly and forks at beginning of prescutellar space; a line of posterior dorso-central white scales on each side that does not reach to middle of scutum; a patch of broad, flat white scales on lateral margin just before level of wing root and few narrow curved white scales over wing root; posterior pronotum with a large patch of broad white scales; post-spiracular scales absent and subspiracular area with white scales; mesepimeral scale patches connected forming a V-shaped white scale patch (Figs. 2, 3). Wing: With dark scales on all veins except for minute basal spot of white scales on costa (Figs. 1, 3); first forked cell 1.5 times as long as its stem. Abdomen: Pale basal bands present on terga II-VII. Legs: Fore and mid-femur dark anteriorly and paler posteriorly; hind femur with a broad white stripe anteriorly which widens at base; fore- and mid- tarsi with basal white bands on tarsomeres 1-2; hind tarsus with basal white bands on tarsomeres 1-4...". The patch of broad flat white scales on lateral margin of the scutum just before level of wing root in Ae. albopictus is a critical character that separates this invasive species from other closely related Afrotropical taxa (Y.-M. Huang, pers. comm). These broad scales can clearly be seen in Fig. 3.

\section{Conclusion}

This report comprises the first confirmed record of the SE Asian tropical invasive vector Ae. albopictus in the densely populated capital city of Matupo in Mozambique and is of high public health significance. Invasive populations of Ae. albopictus have been shown to utilise a diverse range of natural and artificial habitats in West Africa [26-29], and its introduction can greatly affect the distribution and the dynamics of native vectors populations, resulting a new patterns of disease transmission and risk profiles [30, 31]. Additional studies must be encouraged to thoroughly understand the local distribution, behaviour and vector competence of this invasive species, and its interactions with indigenous Aedes (Stegomyia) species, to better support future DEN and CHIK disease transmission disruption and effective vector control strategies in Mozambique.

\section{Competing interests}

The authors declare that they have no competing interests.

\section{Authors' contributions}

Both authors equally contributed to this work. Both collected samples, performed identifications, and co-wrote and approved the final manuscript.

\section{Acknowledgements}

We are thankful to Ussene Ussene Sualé and Adalgiza Pilale (the owners of the patio where mosquitoes were caught) for allowing the publication of this report. We are grateful to Dr Yvonne-Marie Linton, Dr Yiau-Min Huang and Ms. Judith Stoffer from the Walter Reed Biosystematics Unit \& Smithsonian Institutions for assistance with species confirmation and illustrations. The study did not receive funding support. 
Received: 11 December 2015 Accepted: 4 February 2016

Published online: 09 February 2016

\section{References}

1. Gubler DJ, Sather GE, Kuno G, Cabral JR. Dengue 3 virus transmission in Africa. Am J Trop Med Hyg. 1986;35(6):1280-4

2. World Health Organisation. Denque fever outbreak in Mozambique and Tanzania (Situation as of 14 May 2014)[http://www.afro.who.int/en/clustersa-programmes/dpc/epidemic-a-pandemic-alert-and-response/outbreaknews/4137-dengue-fever-outbreak-in-mozambique-and-tanzania-situationas-of-14-may-2014.html ]

3. Gudo ES, Pinto G, Vene S, Mandlaze A, Muianga AF, Cliff J, et al. Serologica evidence of Chikungunya virus among acute febrile patients in southern Mozambique. PLoS Negl Trop Dis. 2015;9(10):e0004146.

4. Mattingly PF. Genetical aspects of the Aedes aegypti problem. I. Taxonomy and bionomics. Ann Trop Med Parasitol. 1957;51(4):392-408.

5. Mattingly PF. Genetical aspects of the Aedes aegypti problem. II. Disease relationships, genetics and control. Ann Trop Med Parasitol. 1958;52(1):5-17.

6. Gubler DJ, Clark GG. Dengue/dengue hemorrhagic fever: the emergence of a global health problem. Emerg Infect Dis. 1995:1(2):55-7.

7. Christopher SR. Aedes aegypti (L.) The yellow fever mosquito: Its life history, bionomics and structure. London: The Syndics of the Cambridge University Press; 1960.

8. Kraemer MU, Sinka ME, Duda KA, Mylne AQ, Shearer FM, Barker CM, et al. The global distribution of the arbovirus vectors Aedes aegypti and Ae. albopictus. eLife. 2015:4:e08347.

9. Worth CB, De Meillon B. Culicine mosquitoes (Diptera: Culicidae) recorded from the province of Mozambique (Portuquese East Africa) and their relation to arthropod-borne virus. Anais Inst Med Trop. 1960;17:231-56.

10. Higa Y, Abilio AP, Futami K, Lazaro MA, Minakawa N, Gudo ES. Abundant Aedes (Stegomyia) aegypti aegypti mosquitoes in the 2014 dengue outbreak area of Mozambique. Trop Med Health. 2015;43(2):107-9.

11. Huang Y-M. The subgenus Stegomyia of Aedes in the Afrotropical Region with keys to the species (Diptera: Culicidae). Zootaxa. 2004;700:1-120.

12. Sylla M, Bosio C, Urdaneta-Marquez L, Ndiaye M, Black II WC. Gene flow, subspecies composition, and dengue virus-2 susceptibility among Aedes aegypti collections in Senegal. PLoS Negl Trop Dis. 2004;3(4):e408.

13. Hawley WA. The biology of Aedes albopictus. J Am Mosq Control Assoc Suppl. 1988;1:1-39.

14. Bonizzoni M, Gasperi G, Chen X, James AA. The invasive mosquito species Aedes albopictus: current knowledge and future perspectives. Trends Parasitol. 2013;29(9):460-8.

15. Juliano SA, O'Meara GF, Morrill JR, Cutwa MM. Desiccation and thermal tolerance of eggs and the coexistence of competing mosquitoes. Oecologia. 2002;130(3):458-69.

16. Reiter $P$, Sprenger $D$. The used tire trade: a mechanism for the worldwide dispersal of container breeding mosquitoes. J Am Mosq Control Assoc. 1987:3(3):494-501.

17. Lounibos PL. Invasions by insect vectors of human diseases. Annual Rev Ent. 2002:47:233-63.

18. Madon MB, Mulla MS, Shaw MW, Kluh S, Hazelrigg JE. Introduction of Aedes albopictus (Skuse) in southern California and potential for its establishment. J Vect Ecol. 2002;27(1):149-54.

19. Johnson BW, Chambers TV, Crabtree MB, Filippis AM, Vilarinhos PT, Resende MC, et al. Vector competence of Brazilian Aedes aegypti and Ae. albopictus for a Brazilian yellow fever virus isolate. Trans Roy Soc Trop Med Hyg. 2002; 96(6):611-3.

20. Paupy C, Delatte H, Bagny L, Corbel V, Fontenille D. Aedes albopictus, an arbovirus vector: from the darkness to the light. Microbes Infect. 2009;11(1415):1177-85

21. Cancrini G, Frangipane di Regalbono A, Ricci I, Tessarin C, Gabrielli S, Pietrobelli M. Aedes albopictus is a natural vector of Dirofilaria immitis in Italy. Vet Parasitol. 2003;118(3-4):195-202.

22. Girod R. First record of Aedes albopictus in Mayotte Island, Comoros archipelago. Parasite. 2004;11(1):74

23. Depoortere E, Coulombier D, Group ECra. Chikungunya risk assessment for Europe: recommendations for action. Euro Surveill. 2006:11(19):e060511.

24. Huang Y-M. Contributions to the Mosquito Fauna of Southeast Asia. XIV. The Subgenus Stegomyia of Aedes in Southeast Asia I - The Scutellaris Group of Species. Contrib Amer Ent Inst. 1972;9(1):1-109.
25. Huang Y-M, Medical Entomology Studies - XI. The subgenus Stegomyia of Aedes in the Oriental Region with keys to the species (Diptera: Culicidae). Contrib Amer Ent Inst. 1979;15(6):1-79.

26. Cornel AJ, Hunt RH. Aedes albopictus in Africa? First records of live specimens in imported tires in Cape Town. J Am Mosq Control Assoc. 1991;7(1):107-8.

27. Jupp PG, Kemp A. Aedes albopictus and other mosquitoes imported in tires into Durban, South Africa. J Am Mosq Control Assoc. 1993;8:321-2.

28. Simard F, Nchoutpouen E, Toto JC, Fontenille D. Geographic distribution and breeding site preference of Aedes albopictus and Aedes aegypti (Diptera: culicidae) in Cameroon. Central Africa J Med Entomol. 2005:42(5):726-31.

29. Kamgang B, Ngoagouni C, Manirakiza A, Nakoune E, Paupy C, Kazanji M. Temporal patterns of abundance of Aedes aegypti and Aedes albopictus (Diptera: Culicidae) and mitochondrial DNA analysis of Ae. albopictus in the Central African Republic. PLoS Negl Trop Dis. 2013;7(12):e2590.

30. Gubler DJ. Aedes albopictus in Africa. Lancet Infect Dis. 2003;3(12):751-2.

31. Ngoagouni C, Kamgang B, Nakoune E, Paupy C, Kazanji M. Invasion of Aedes albopictus (Diptera: Culicidae) into central Africa: what consequences for emerging diseases? Parasites \& Vectors. 2015;8:191-8.

\section{Submit your next manuscript to BioMed Central and we will help you at every step:}

- We accept pre-submission inquiries

- Our selector tool helps you to find the most relevant journal

- We provide round the clock customer support

- Convenient online submission

- Thorough peer review

- Inclusion in PubMed and all major indexing services

- Maximum visibility for your research

Submit your manuscript at www.biomedcentral.com/submit
C) BioMed Central 